\title{
AnÁlise de Elementos Químicos em Cabelo: PeRsPetiva histórica, POTENCIALIDADES, CONTROVÉRSIAS E DESAFIOS ANALITIICOS
}

\author{
César Tavares ${ }^{a, b}$, Joana Coimbra ${ }^{b}$, Carlos Vale ${ }^{c}$, Eduarda Pereira ${ }^{\text {*a.b,d }}$ \\ a Departamento de Química, Universidade de Aveiro \\ b Laboratório Central de Análises, Universidade de Aveiro \\ c Centro Interdisciplinar de Investigação Marinha e Ambiental, Universidade do Porto \\ ${ }^{\mathrm{d}}$ Centro de Estudos do Ambiente e do Mar, Universidade de Aveiro \\ eduper@ua.pt
}

\begin{abstract}
Analysis of Chemical Elements in Hair: historical perspective, capabilities, controversies and analytical challenges - Several studies have reported the quantification of organic drugs and chemical elements in human hair, despite the uncertainties related with the validity of the analytical results, in particular when the analytes are chemical elements. However it is indisputable the usefulness of the chemical analysis of hair for toxicological applications, such as forensics, clinical diagnostics and evaluation of environmental exposure.

This paper is focused on the analytical constraints and challenges in quantifying minor and trace elements in hair. The main topics are the characteristics of human hair, the historical evolution of hair chemical analysis, the controversy associated with this type of analysis, and the main advantages and disadvantages of this type of matrix compared with other common biological matrices. A special emphasis is given to hair washing, which is one of the most controversial steps on the analytical procedure. The importance of the validation of analytical systems and the implementation of strategies for results quality assurance and control is also mentioned.
\end{abstract}

V́rios trabalhos têm descrito a quantificação de drogas orgânicas e elementos químicos em cabelo humano, embora persistam incertezas sobre a validade analítica dos resultados, principalmente quando os analitos são elementos químicos. No entanto, é indiscutível a utilidade da análise química de cabelo em várias aplicações toxicológicas, tais como análise forense, diagnósticos clínicos e avaliação da exposição ambiental.

O foco deste artigo são as limitações e os desafios da quantificação de elementos químicos minoritários e vestigiais em cabelo. Os principais tópicos são as características do cabelo humano, a evolução histórica da análise química de cabelo, a controvérsia existente em torno deste tipo de análise, e as principais vantagens e desvantagens deste tipo de matriz comparativamente a outras matrizes biológicas comuns. É dado um especial destaque à lavagem do cabelo, uma das etapas mais controversas do procedimento analítico. A importância da validação de sistemas analíticos e da implementação de estratégias de controlo e garantia da qualidade dos resultados é também referida.

\section{Principals CARACTERÍSTICAS BIOLÓGICAS E FíSICO-QUímICAS DO CABELO}

Os pelos, nomeadamente os que revestem o crânio humano (cabelo), podem ser vistos como uma "área de quarentena biológica”, onde se acumulam substâncias excretadas pelo organismo [1]. A anatomia dos pelos e as suas interações com o ambiente e com as estruturas da pele influenciam a acumulação de substâncias nessa matriz [2]. Assim, a correta interpretação dos resultados obtidos em análises químicas do cabelo exige um entendimento básico das características biológicas e físico-químicas dessa estrutura.

Os cabelos formam-se em invaginações da epiderme, chamadas de folículos pilosos, e são constituídos maioritariamente por células mortas queratinizadas [2]. Uma fibra de cabelo pode ser dividia em três camadas: cutícula, córtex e medula (Figura 1) [2].

A superfície do cabelo é formada por células sobrepostas em várias camadas, de forma análoga a telhas num telhado, constituindo a cutícula [3]. O córtex, que corresponde à maioria da massa do cabelo (70-90\%), é revestido pela cutícula e contém células fusiformes alinhadas segundo o eixo longitudinal das fibras de cabelo [3]. Os cabelos mais grossos possuem frequentemente uma estrutura central porosa, chamada de medula [3].

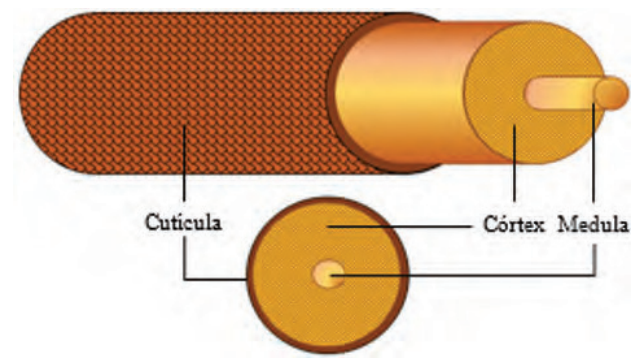

Figura 1 - Principais estruturas constituintes da fibra de cabelo. Figura adaptada da referência [2]

Um fio de cabelo é essencialmente um material compósito natural que integra uma rede polimérica parcialmente cristalina de fibras cilíndricas bem compactadas, constituídas por uma família de proteínas designada por "queratina", denominadas como microfibrilas ou filamentos intermédios de queratina (KIF), embutidas numa matriz amorfa composta por proteínas associadas à queratina (KAP) e por lípidos estruturais (Figura 2) [2,4-6]. 


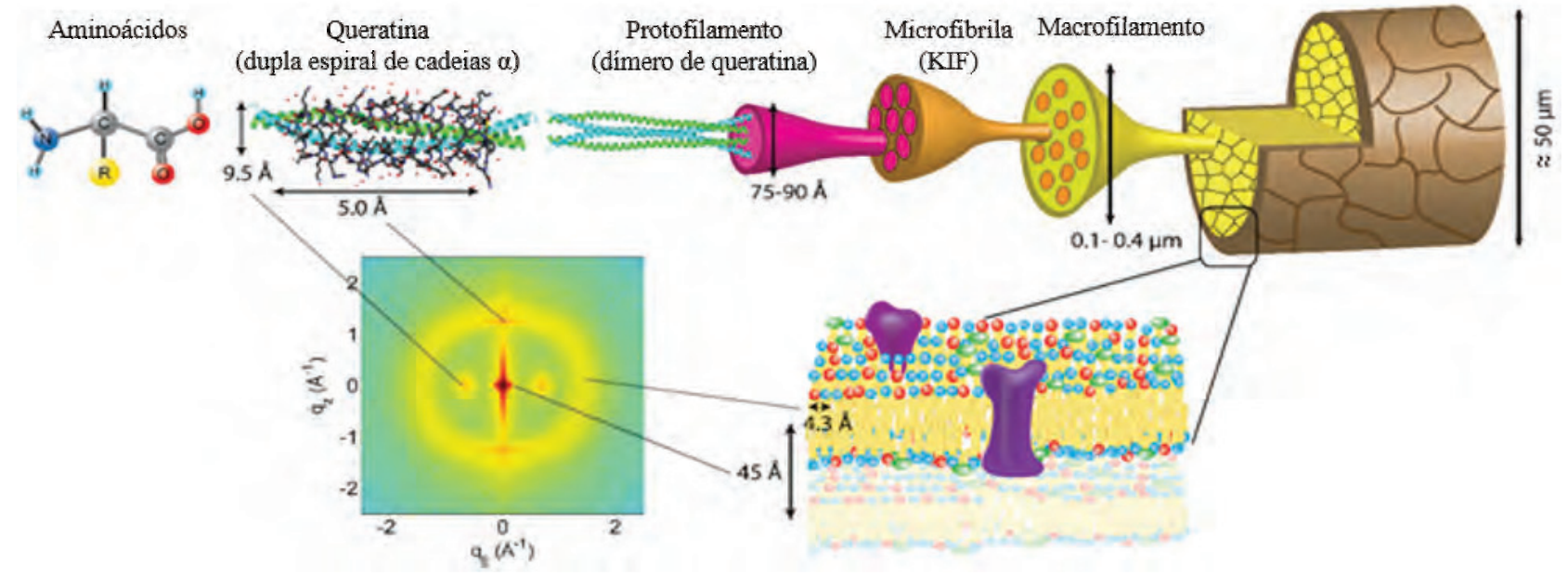

Figura 2 - Modelo de organização hierárquica das estruturas proteicas constituintes da fibra de cabelo [3-6]. O padrão de difração de raios X obtido reflete algumas das estruturas da fibra e respetivas dimensões. Figura adaptada da referência [6]

Dependendo do seu teor de humidade, o cabelo humano consiste em $65-95 \%$ de proteínas, 1-9\% de lípidos, pigmentos (melanina) e elementos vestigiais $(<1 \%)$ [2], o que corresponde a aproximadamente 50\% de carbono (C), 7\% de hidrogénio $(\mathrm{H}), 22 \%$ de oxigénio $(\mathrm{O}), 16 \%$ de nitrogénio $(\mathrm{N}), 5 \%$ de enxofre $(\mathrm{S})$ e percentagens vestigiais de outros elementos [4]. O elevado conteúdo de enxofre deve-se à abundância de grupos tiol (-SH) e dissulfureto (-S-S) que contribuem para a manutenção da identidade estrutural do cabelo e para a sua elevada resistência e estabilidade [2]. Os lípidos estão localizados internamente e à superfície da fibra, ligando-se covalentemente ou por ligações mais fracas (pontes de hidrogénio e interações de van der Waals) [3]. O lípido mais comum na cutícula é o ácido 18-metilicosanóico, que forma ligações tioéster a partir dos gruos tiol da superfície da fibra $[3,4]$. Os elementos vestigiais ligam-se a grupos funcionais das cadeias laterais dos aminoácidos constituintes das proteínas ou a grupos ácidos dos lípidos [2].

O cabelo tem um comportamento global hidrofílico, embora a sua superfície (cutícula) seja maioritariamente hidrofóbica, o que se deve à presença de cadeias apolares de lípidos na superfície do cabelo e de grupos químicos polares dos resíduos de aminoácidos no interior da fibra (córtex e medula) [4]. Cabelos saudáveis podem conter até cerca de 35\% de água, dependendo essa percentagem da humidade relativa do ar e do desgaste das fibras devido, por exemplo, a tratamentos capilares [2,4]. A água no cabelo provém também da génese das fibras, pois durante a queratinização ocorre a eliminação do núcleo das células e a produção desmedida de queratina que, ao acumular-se no citoplasma, provoca a libertação de água e a morte celular [2,7].

O desenvolvimento de cada fibra de cabelo ocorre num ciclo envolvendo três fases principais [2,3] (Figura 3):

1. Anagénese (crescimento): fase de crescimento da fibra, devido à intensa atividade metabólica no bolbo piloso, que se prolonga normalmente entre 2 a 6 anos.

2. Catagénese (transição): fase na qual ocorre um decréscimo na atividade metabólica do bolbo, o que leva à apoptose das células aí existentes; verifica-se a migração do bolbo em direção à superfície da epiderme, com atrofia do folículo; fase com a duração de algumas semanas.

3. Telogénese (repouso): fase que se caracteriza pela cessação completa do crescimento da fibra e atrofia do folículo, com a duração de 4 a 8 semanas.

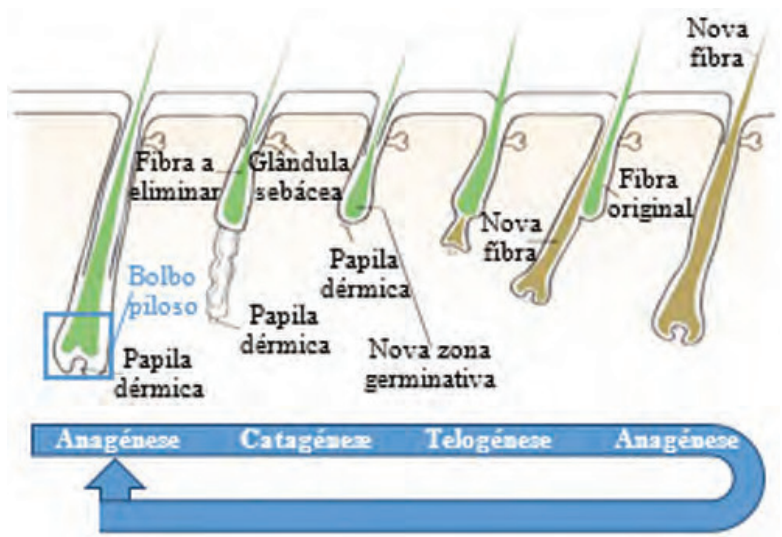

Figura 3 - Ciclo de desenvolvimento dos folículos pilosos e geração de novas fibras capilares. Figura adaptada da referência [8]

A aproximação do bolbo a um depósito de células estaminais ativa o crescimento de uma nova fibra [3], provocando a expulsão da antiga e a regeneração de todo o folículo, retomando-se a anagénese, a fase na qual ocorre a incorporação de substâncias químicas na fibra a partir dos vasos sanguíneos no bolbo [9]. Cerca de 85\% dos folículos existentes no couro cabeludo saudável encontram-se em anagénese, enquanto os restantes 15\% em telogénese [7]. Contaminações com níveis elevados de elementos metálicos de elevada toxicidade, tais como tálio, cádmio e mercúrio podem acelerar a transição da anagénese para a catagénese [10].

\section{MECANISMOS DE INCORPORAÇÃO DE ELEMENTOS QUÍMICOS NO CABELO}

Na Figura 4 são representadas algumas das formas de incorporação de substâncias químicas no cabelo. Embora os mecanismos de incorporação apresentados tenham sido demonstrados originalmente para drogas orgânicas [11], estes são também aplicáveis a elementos químicos [7,12]. 
Os elementos químicos podem associar-se ao cabelo, endógena ou exogenamente, por interações eletrostáticas ou através de ligações covalentes com queratina, melanina ou lípidos. O número de eletrões de valência e o tamanho da partícula definem o tipo e a força da ligação estabelecida [13]. A maioria dos elementos metálicos apresenta grande afinidade por grupos tiol [14], embora os grupos carboxilo sejam também importantes na ligação desse tipo de elementos às fibras de cabelo [15].

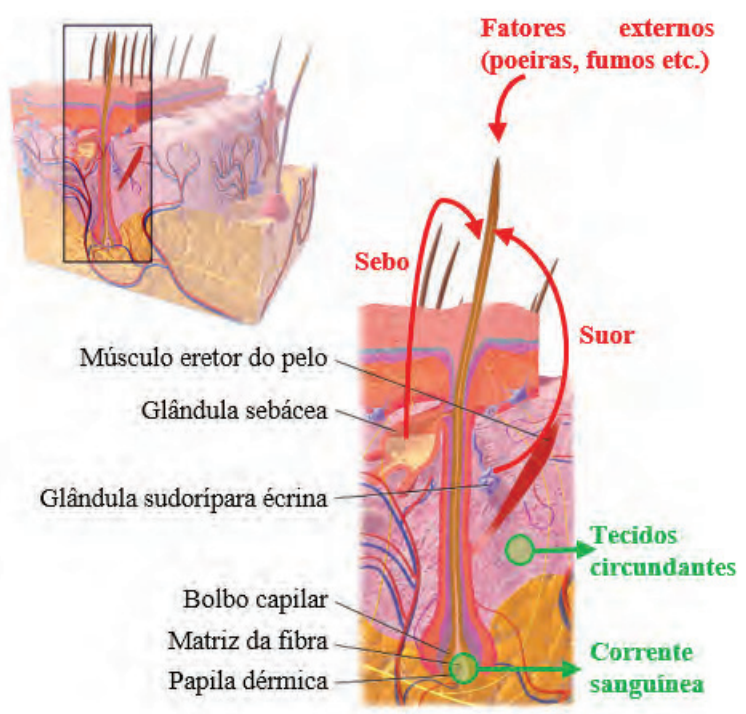

Figura 4 - Principais estruturas do folículo piloso e alguns dos fatores que influenciam a incorporação de substâncias químicas em cabelos. Os mecanismos de incorporação endógena e exógena estão assinalados a verde e vermelho, respetivamente. Figura adaptada das referências [7] e [16]

Relativamente à incorporação endógena, o modelo mais simples assume que esta ocorre devido ao gradiente de concentração entre a fibra de cabelo e os fluidos circundantes (sangue, linfa e outros tipos de fluidos extracelulares), numa extensão de 1,2 a 1,5 mm entre a base do folículo e a zona de queratinização [7]. Quanto à contaminação exógena, esta pode ocorrer de várias formas, envolvendo fatores externos e a deposição de suor e sebo na superfície do cabelo [15]. Alguns elementos transportados por poeiras podem ser retidos nos espaços entre as células da cutícula, principalmente quando esta estiver danificada [10]. A adsorção de vários elementos ao cabelo depende do pH da fibra e do ambiente envolvente, o que sugere que o cabelo é um permutador iónico [15].

Perspetiva HISTÓRICA dA ANÁLISE QUÍMICA dE CABELO HUMANO, MASSIFICAÇÃO DOS SERVIÇOS COMERCIAIS DE QUANTIFICAÇÃO DE ELEMENTOS QUÍMICOS EM CABELO E A CONTROVÉRSIA ASSOCIADA

Na Figura 5 são apresentados alguns marcos históricos relacionados com a análise química de cabelo. Os eventos mais recentes e os mais antigos são representados, respetivamente, mais próximos da raiz (cabelo mais recente) e mais próximos das pontas (cabelo mais antigo).

Os desenvolvimentos científicos e tecnológicos das décadas de 1970 e 1980 levaram a que vários laboratórios, muitos com competência analítica duvidosa, começassem a comercializar serviços de análise química de cabelo, principalmente nos E.U.A. [17]. A crescente procura desse tipo de serviços foi suportada, em parte, na popularidade adquirida pela hipótese apresentada em alguns trabalhos científicos, referente à utilização do cabelo para avaliar o estado nutricional [17]. Todavia, surgiram entretanto várias publicações que contestavam a validade da análise química de cabelo, gerando alguma controvérsia [18-22]. Atualmente, este tipo de serviços é ainda bastante popular nos E.U.A. o que se reflete, por exemplo, na publicação de alguns livros por autores norte-americanos [23-25] e na referência à análise de cabelo para a deteção de elementos químicos perigosos em alguns episódios das conhecidas séries de televisão “House M.D.” e “CSI: Crime Scene Investigation” [26-28].

No trabalho de Barrett (1985) [21] foram enviadas amostras de cabelo de duas adolescentes saudáveis para vários laboratórios comerciais, verificando-se a obtenção de uma grande disparidade entre os valores de concentração reportados para alguns elementos em amostras supostamente idênticas. Verificou-se também a apresentação de conclusões potencialmente assustadoras para alguns pacientes, assim como divergência quanto aos níveis de concentração considerados "normais” e aos tratamentos com suplementos alimentares que deveriam ser implementados. Embora o trabalho de Barret (1985) apresente algumas lacunas, nomeadamente na amostragem do cabelo [29], a maioria das objeções aí mencionadas são válidas, sendo consensual que existiam falhas nos métodos usados pelos laboratórios que comercializavam serviços de análise química de cabelo [17]. Trabalhos análogos ao referido foram publicados em 2001 [30], 2002 [31] e 2013 [32], envolvendo laboratórios dos E.U.A., Alemanha e Coreia do Sul. Os trabalhos publicados em 2001 e 2002 apresentam o mesmo tipo de conclusões do trabalho de Barret (1985), o que originou uma troca de críticas entre o primeiro autor do trabalho publicado em 2001 (Seidel) e representantes de alguns dos laboratórios norte-americanos avaliados [33-35]. No trabalho publicado em 2013, verificou-se um grau de concordância razoável entre as concentrações obtidas por diferentes laboratórios, mas um grau de discordância significativo quanto aos intervalos de concentração considerados “normais".

A pesquisa bibliográfica realizada no contexto deste trabalho permitiu constatar que o número de publicações referentes à análise química de cabelo humano, nomeadamente a quantificação de elementos químicos nessa matriz, tem vindo a seguir uma tendência claramente crescente nos últimos anos, o que pode ser explicado, em parte, pelos avanços científicos e tecnológicos e pela inexistência de consenso relativamente às conclusões apresentadas nos trabalhos publicados. Essa falta de consenso deve-se a vários fatores, entre os quais as lacunas em termos de estratégias de controlo e garantia da qualidade dos resultados. Neste contexto, nas últimas décadas, tem-se verificado uma maior preocupação com as questões da qualidade na análise química de cabelo, o que se refletiu no início da 
produção e comercialização de materiais de referência certificados para essa matriz [12] e na criação de um programa de ensaios de comparação interlaboratorial para a quantificação de elementos químicos em cabelo (e outras matrizes biológicas) (QMEQAS) [36]. A Society of Hair Testing (SoHT), fundada em 1995, tem vindo também a organizar encontros e workshops, para discutir o uso de cabelo para fins analíticos, coordenando ensaios de comparação interlaboratorial, para análise de drogas orgânicas em cabelo, e criando vários documentos que apoiam a realização de análises químicas de cabelo [37]. O maior foco desta organização na análise química de cabelo para a quantificação de drogas orgânicas é explicado pela existência de um maior consenso quanto à validade deste tipo de análise, comparativamente ao que se verifica para os elementos químicos, o que se reflete na sua aplicação em vários contextos: exposição pré-natal, controlo antidoping, abuso sexual facilitado por drogas, abuso de álcool, etc. [38].

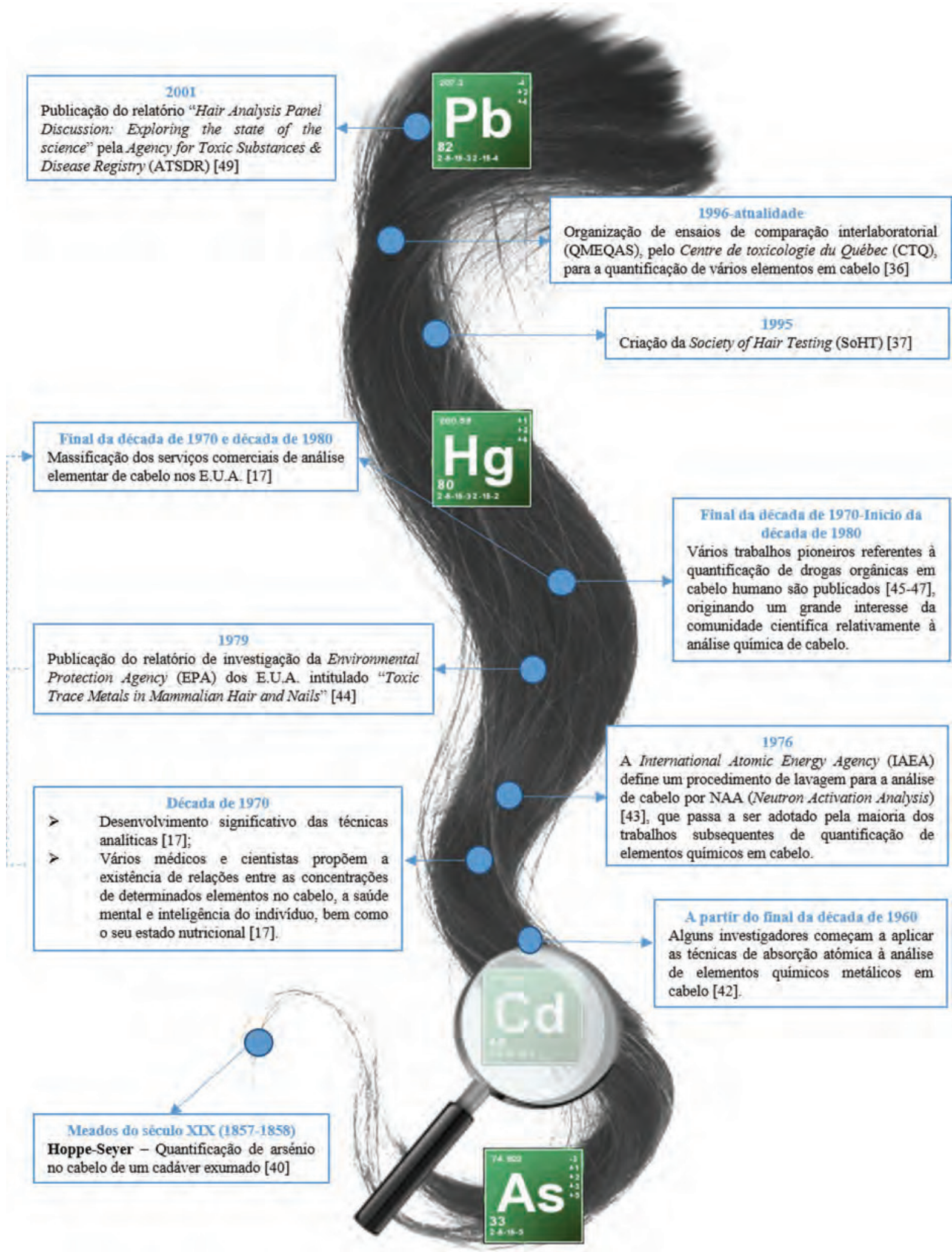

Figura 5 - Alguns marcos históricos importantes referentes à análise química de cabelo [17,39] 


\section{ANÁLISE QUIIMICA DE CABELOS DE PERSONALIDADES HISTÓRICAS}

Desde meados do século $\mathrm{XX}$, foram publicados vários trabalhos de quantificação de elementos tóxicos em cabelos de personalidades históricas [50,51], alguns dos quais são referidos na Tabela 1. As conclusões apresentadas nesses tra- balhos são bastante controversas, particularmente nos casos de Napoleão e Beethoven, resultando num grande número de publicações, como se pode verificar na Tabela 1 . As controvérsias existentes devem-se principalmente à dificuldade em identificar a origem endógena ou exógena dos elementos quantificados.

Tabela 1 - Tabela-resumo referente à análise de elementos químicos em cabelos de quatro personalidades históricas [50,51]. Os intervalos de referência (IR) indicados foram retirados de Goullé (2006) [12] e correspondem a uma amostra de indivíduos saudáveis e a um nível de confiança de 95\%

\begin{tabular}{|c|c|c|c|c|}
\hline $\begin{array}{l}\text { Personalidades } \\
\text { históricas }\end{array}$ & $\begin{array}{c}\text { Concentrações de } \\
\text { elementos no cabelo }\end{array}$ & $\begin{array}{l}\text { Alguns sintomas } \\
\text { verificados }\end{array}$ & $\begin{array}{l}\text { Possíveis fontes } \\
\text { de exposição }\end{array}$ & Referências \\
\hline $\begin{array}{l}\text { Napoleão Bonaparte } \\
\text { (imperador francês) } \\
\text { (1769-1821) [52] }\end{array}$ & $\begin{array}{c}\text { Valores máximos de } \\
\text { concentração: } \\
\text { As: } 51,2 \mu \mathrm{g} / \mathrm{g} \\
\text { IR: } 2,6-17,8 \mu \mathrm{g} / \mathrm{g} \\
\text { Sb: } 4,47 \mu \mathrm{g} / \mathrm{g} \\
\text { IR: } 0,05-0,13 \mu \mathrm{g} / \mathrm{g} \\
\text { Hg: } 4,68 \mu \mathrm{g} / \mathrm{g} \\
\text { IR: } 0,94-8,13 \mu \mathrm{g} / \mathrm{g} \\
\text { Pb: } 229,2 \mu \mathrm{g} / \mathrm{g} \\
\text { IR: } 0,13-4,57 \mu \mathrm{g} / \mathrm{g} \\
\text { (Data de recolha das } \\
\text { amostras: } 1 \text { dia após } \\
\text { a morte de Napoleão) }\end{array}$ & $\begin{array}{l}\text { Vasto conjunto de sinto- } \\
\text { mas (que dificultam a ob- } \\
\text { tenção de um diagnóstico } \\
\text { claro), tais como perda } \\
\text { rápida de peso (consis- } \\
\text { tente com a hipótese de } \\
\text { cancro do estômago), } \\
\text { distúrbios gastrointes- } \\
\text { tinais (melena, cólicas, } \\
\text { vómitos, prisão de ventre } \\
\text { alternada com diarreia, } \\
\text { etc.), febre e fraqueza } \\
\text { progressiva }\end{array}$ & $\begin{array}{c}\text { As: (Ver texto) } \\
\text { Sb: Tartarato de an- } \\
\text { timónio e potássio } \\
\text { (emético prescrito a } \\
\text { Napoleão nos seus } \\
\text { últimos meses de } \\
\text { vida) } \\
\text { Hg: Calomelano } \\
\left(\mathrm{Hg}_{2} \mathrm{Cl}_{2}\right) \text {, usado como } \\
\text { laxante. } \\
\text { Pb: óxido de chumbo } \\
\text { (adicionado a vinhos } \\
\text { para os adoçar) }\end{array}$ & [53-61] \\
\hline $\begin{array}{l}\text { Ludwig van Beethoven } \\
\text { (compositor alemão) } \\
(1770-1827)[62]\end{array}$ & $\begin{array}{l}\text { Valor médio de con- } \\
\text { centração: } \\
\text { Pb: } 60 \mu \mathrm{g} / \mathrm{g} \\
\text { (Data de recolha da } \\
\text { amostra: } 1 \text { dia após a } \\
\text { morte de Beethoven) }\end{array}$ & $\begin{array}{l}\text { Distúrbios gastrointesti- } \\
\text { nais frequentes (sintomas } \\
\text { típicos de envenenamen- } \\
\text { to com chumbo), tais } \\
\text { como cólicas, diarreia, } \\
\text { vómitos e gota, ansieda- } \\
\text { de, perda de audição e } \\
\text { cirrose. }\end{array}$ & $\begin{array}{l}\text { Acetato de chumbo } \\
\text { (usado como ado- } \\
\text { çante em vinho), } \\
\text { utensílios de cerâmi- } \\
\text { cos revestidos com } \\
\text { esmalte contendo } \\
\text { chumbo. Tratamen- } \\
\text { to de pneumonia e } \\
\text { adesivos usados em } \\
\text { paracenteses. }\end{array}$ & [63-65] \\
\hline $\begin{array}{c}\text { Andrew Jackson } \\
\text { (7. }{ }^{\circ} \text { presidente dos } \\
\text { E.U.A.) } \\
(1767-1845)[66]\end{array}$ & $\begin{array}{l}\text { Valores médios de } \\
\text { concentração: } \\
\text { Amostra recolhida } \\
\text { em } 1815: \\
\text { Hg: } 6,0 \mu \mathrm{g} / \mathrm{g} \\
\text { Pb: } 130,5 \mu \mathrm{g} / \mathrm{g} \\
\text { Amostra recolhida } \\
\text { em } 1839: \\
\text { Hg: } 5,6 \mu \mathrm{g} / \mathrm{g} \\
\text { Pb: } 44 \mu \mathrm{g} / \mathrm{g}\end{array}$ & $\begin{array}{c}\text { Salivação excessiva, } \\
\text { perda rápida de dentes, } \\
\text { cólicas, diarreia, palidez, } \\
\text { tremores, irritabilidade, } \\
\text { paranoia, mudanças de } \\
\text { humor violentas, insufi- } \\
\text { ciência renal (sintomas } \\
\text { compatíveis com enve- } \\
\text { nenamento com mercú- } \\
\text { rio e chumbo) }\end{array}$ & $\begin{array}{c}\text { Uso terapêutico de } \\
\text { calomelano e açúcar } \\
\text { de chumbo (acetato } \\
\text { de chumbo); } \\
\text { Balas de chumbo } \\
\text { (Andrew Jackson foi } \\
\text { alvejado em } 1806 \text { e } \\
\text { 1813 e uma das balas } \\
\text { ficou alojada no seu } \\
\text { corpo durante cerca } \\
\text { de } 20 \text { anos.) }\end{array}$ & [67] \\
\hline $\begin{array}{c}\text { Charles Hall } \\
\text { (explorador norte-ame- } \\
\text { ricano) } \\
\text { (1821-1871) [68] }\end{array}$ & 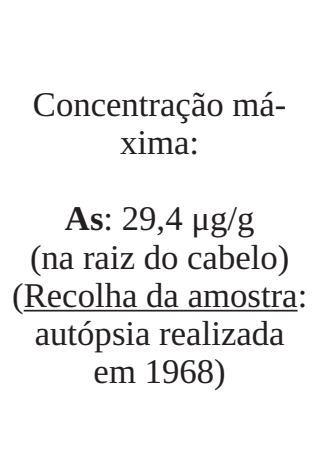 & $\begin{array}{l}\text { Distúrbios gastrointes- } \\
\text { tinais e problemas neu- } \\
\text { rológicos (demência), } \\
\text { após o consumo de uma } \\
\text { chávena de café, nas } \\
\text { duas semanas que ante- } \\
\text { cederam o falecimento } \\
\text { (sintomas típicos de } \\
\text { intoxicação aguda com } \\
\text { arsénio) }\end{array}$ & $\begin{array}{l}\text { Envenenamento } \\
\text { (Charles Hall acusou } \\
\text { os seus colegas de } \\
\text { tripulação de o terem } \\
\text { envenenado). A de- } \\
\text { teção de uma maior } \\
\text { concentração de arsé- } \\
\text { nio na raiz do cabelo } \\
\text { é consistente com a } \\
\text { hipótese de exposição } \\
\text { aguda nas duas últi- } \\
\text { mas semanas de vida. }\end{array}$ & [69] \\
\hline
\end{tabular}


O relatório da autópsia ao corpo de Napoleão sugere cancro no estômago como possível causa da morte [70], sendo esta hipótese defendida pela maioria dos historiadores [71], devido à predisposição genética do imperador francês [72] e por alguns dos sintomas revelados durante o exílio na ilha de Santa Helena (os seus últimos anos de vida) [54,55]. Todavia, análises recentes revelaram uma concentração alta de arsénio nos cabelos de Napoleão [56-61], o que levou alguns investigadores a defender uma hipótese alternativa para a sua causa de morte: envenenamento com arsénio. No contexto da controvérsia existente em torno dessa hipótese, Ben Weider (Figura 6) enviou amostras de cabelo de Napoleão para várias entidades com serviços de análise toxicológicas [73], entre as quais o Federal Bureau of Investigation (FBI) (Figura 7), o Laboratório de Toxicologia do Instituto de Medicina Legal de Estrasburgo, em 2002 e o Laboratório ChemTox (sediado também em Estrasburgo), em 2005, obtendo resultados [56,60,61] que confirmam as altas concentrações de arsénio obtidas nas análises realizadas no início da década de 1960 [57-59].

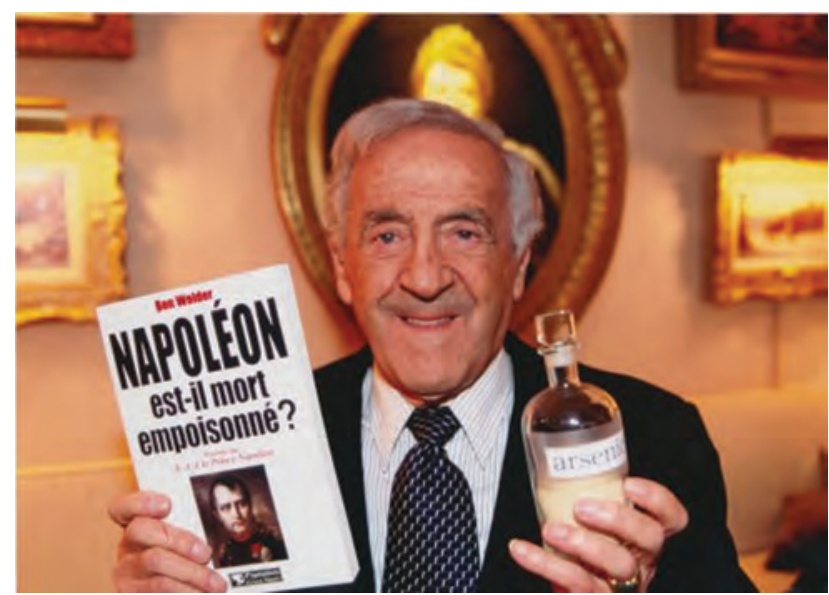

Figura 6 - Ben Weider (1924-2008), fundador da International Napoleonic Society (INS) e um dos principais defensores da teoria de envenenamento com arsénio como causa da morte de Napoleão. Imagem proveniente da referência [74], reproduzida com a autorização da INS

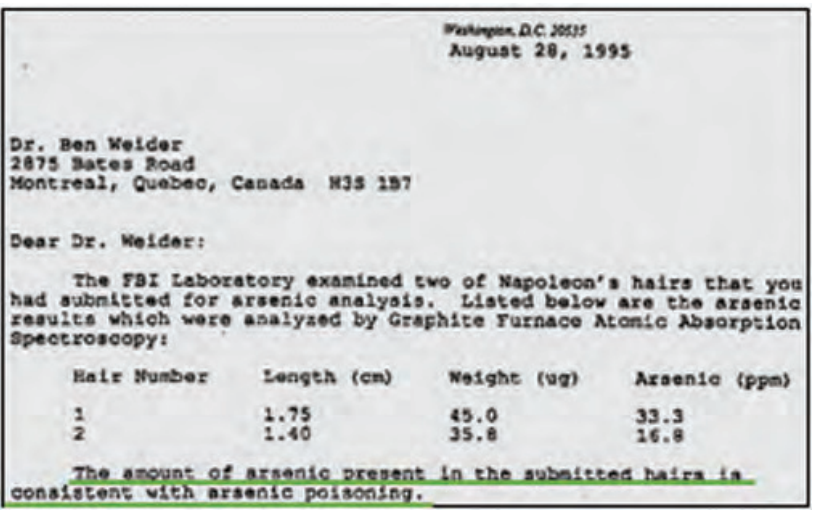

Figura 7 - Carta enviada pelo FBI, a Ben Weider, em 1995, onde se declara que os valores de concentração de arsénio detetados em cabelos de Napoleão são consistentes com a hipótese de envenenamento. Imagem proveniente da referência [75], reproduzida com a autorização da INS

Um dos principais argumentos envolvidos na discussão da causa da morte de Napoleão é a possibilidade de grande parte do arsénio detetado no cabelo provir de contaminações externas, que incluem: pigmentos do papel de parede existente na casa onde Napoleão passou os últimos anos de vida, exposição ao fumo da queima de carvão, uso de produtos cosméticos e de materiais conservantes contendo arsénio para preservação das amostras de cabelo [53].

Em 2003, Pascal Kintz, um dos toxicologistas mais reconhecidos na área da análise química de cabelo (membro do grupo fundador da Society of Hair Testing (SoHT) e autor de vários livros e artigos científicos sobre a análise química de cabelo) e Robert Wenning, professor da Universidade de Luxemburgo, recorreram a uma técnica inovadora de espetrometria de massa, para tentar avaliar a proveniência do arsénio nos cabelos de Napoleão, através da análise da distribuição desse elemento ao longo da secção transversal das fibras de cabelo do imperador francês [73]. Na Figura 8 são apresentadas algumas das imagens obtidas nesse trabalho, expostas numa conferência em 2005 (que pode ser visualizada através do URL (endereço da web) indicado na referência [76]). As zonas brilhantes dessa imagem correspondem a uma maior concentração de arsénio. Assim, verifica-se uma maior acumulação de arsénio na zona da medula, sendo essa observação atribuída à incorporação a partir da corrente sanguínea, apoiando a hipótese de envenenamento [73,76]. Porém, alguns trabalhos indicam a inexistência de uma distribuição definida de arsénio na fibra de cabelo em função da sua forma de incorporação [77], o que enfraquece a justificação apresentada para sustentar a hipótese de envenenamento. Neste contexto, a controvérsia em torno da causa da morte de Napoleão parece permanecer, sendo incerto se será possível vir a obter uma resposta inequívoca.
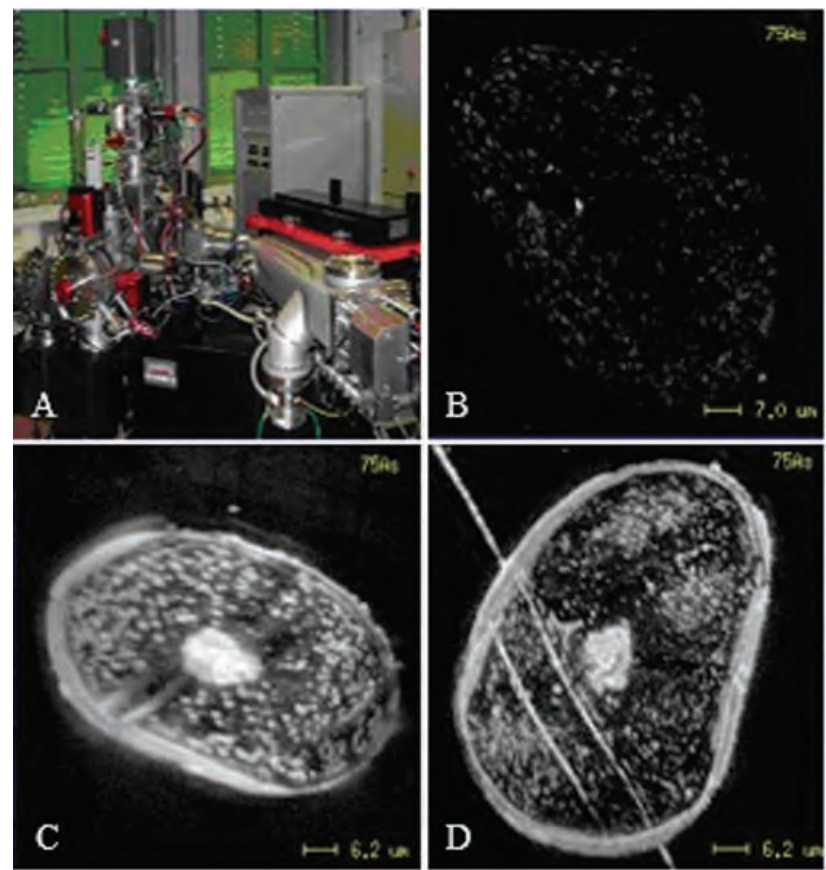

Figura 8 - A: Equipamento de Nano-Secondary Ion-Mass Spectrography (Nano-SIMS) da Universidade de Luxemburgo usado na obtenção das imagens B, C e D para a análise da distribuição de arsénio em secções transversais de fios de cabelo; B: Cabelo não contaminado; C: Cabelo de Napoleão (Abbé Vignali - amostra recolhida a 06/05/1821); D: Cabelo de Napoleão (Las Cases - amostra recolhida a 16/10/1816). As zonas mais brilhantes correspondem a uma maior concentração de arsénio. Imagens provenientes das referências [73] e [76], reproduzidas com a autorização da INS 
O URL indicado na referência [78] permite a visualização de um vídeo que inclui um pequeno resumo das teorias referentes à causa da morte de Napoleão acompanhado de curtos depoimentos de Ben Weider e Pascal Kintz.

A localização do cabelo na parte externa do corpo é uma característica com carácter paradoxal, pois torna a sua recolha muito fácil, o que é uma vantagem, mas aumenta a suscetibilidade a contaminações devidas ao ambiente externo, o que é a principal desvantagem deste tipo de matriz.

Na Figura 9 é apresentado um resumo das principais vantagens e desvantagens do cabelo como matriz analítica comparativamente a outras matrizes biológicas comuns. desse procedimento, devido à baixa eficiência na remoção de alguns contaminantes [80], e pela danificação que a acetona provoca na cutícula, o que facilita a perda/extração de elementos depositados endogenamente e a possível introdução de contaminações externas no interior das fibras de cabelo [81].

Alguns investigadores defendem procedimentos de análise de cabelo sem qualquer etapa de lavagem [82], alegando que esta poderá ser a maior fonte de variabilidade nos resultados obtidos [12]. A argumentação é sustentada, em parte, no facto da variabilidade associada aos resultados obtidos por diferentes laboratórios, para uma mesma amostra de cabelo não sujeita a lavagem durante o respetivo pré-

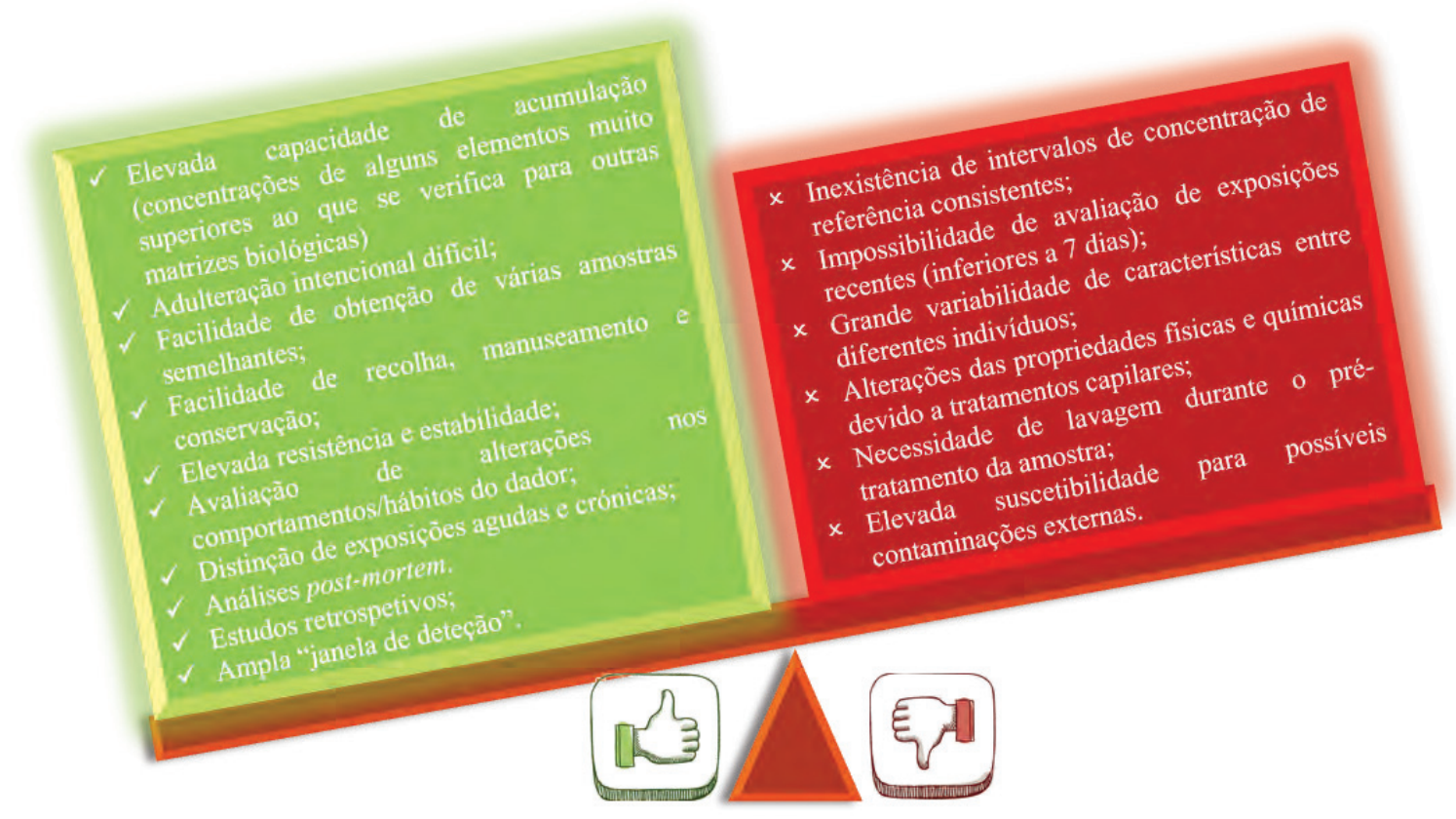

Figura 9 - Principais vantagens e desvantagens do cabelo humano como matriz analítica, comparativamente às outras matrizes biológicas mais comuns (sangue e urina) [7,9,10,38,44,51,79]

\section{Problemas associados à laVagem de cabelo no Pré- -TRATAMENTO DA AMOSTRA: LAVAR OU NÃO LAVAR? EIS A QUESTÃO...}

A concretização do objetivo de analisar quimicamente o cabelo exige frequentemente que as concentrações determinadas nesta matriz sejam representativas da incorporação endógena dos analitos. Neste contexto, verifica-se a existência de muitos procedimentos de extração e lavagem para o pré-tratamento de amostras de cabelo, que são aplicados para minimizar a influência da incorporação exógena (gorduras, poeiras, suor, etc.). Os procedimentos de lavagem mais usados podem ser agrupados em cinco categorias principais, tal como indicado na Figura 10.

O método de lavagem de cabelo recomendado pela IAEA (publicado em 1976), que consiste em lavagens sucessivas com água ultrapura e acetona [43], parece ser o mais usado nos vários trabalhos referentes à quantificação de elementos químicos em cabelo [79]. Contudo, alguns investigadores apresentam objeções relativamente ao uso

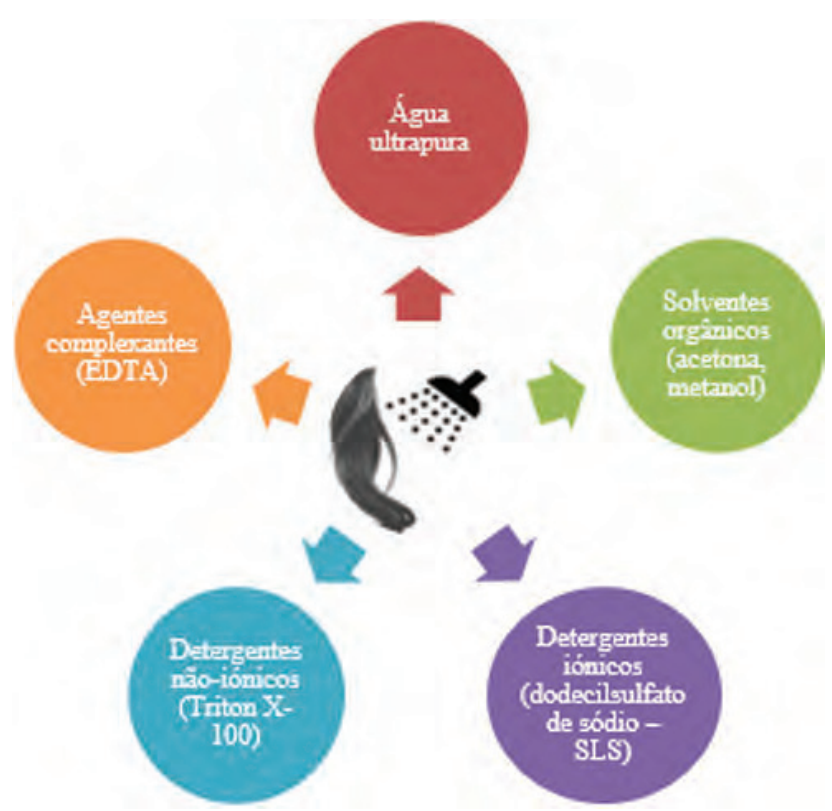

Figura 10 - Solventes e reagentes usados mais frequentemente na lavagem de cabelo durante o pré-tratamento das amostras [50] 
-tratamento ser, para alguns elementos, significativamente inferior ao que se verifica em procedimentos com etapas de lavagem, tal como demonstrado num trabalho publicado em 2002 [50]. A exclusão da etapa de lavagem poderá ter interesse em aplicações forenses, pois a lavagem pode alterar significativamente a composição da amostra de cabelo, com perda da sua identidade característica e diferenciadora [82]. Quando o objetivo da análise implica a minimização da influência das contaminações externas, os defensores dos procedimentos sem etapas de lavagem propõem o uso de amostras sujeitas a um mínimo de contaminação externa. Nesta perspetiva, o tipo ideal de amostra seriam pelos que estivessem confinados unicamente ao interior do folículo [82]. Como é impraticável obter esse tipo de amostras, poderão ser usadas fibras que tenham estado pouco tempo no exterior da pele. Um tipo de amostra que cumpre esses requisitos são os pelos da barba recente, existindo algumas publicações referentes à quantificação de metais nessa matriz $[83,84]$.

\section{ETAPAS DA QUANTIFICAÇÃO DE ELEMENTOS QUÍMICOS EM CABELO}

Como o cabelo é uma matriz com alguma complexidade, a quantificação de elementos químicos nesse tipo de amostra requer um procedimento com várias etapas, o qual é representado na Figura 11 e descrito nos próximos parágrafos.

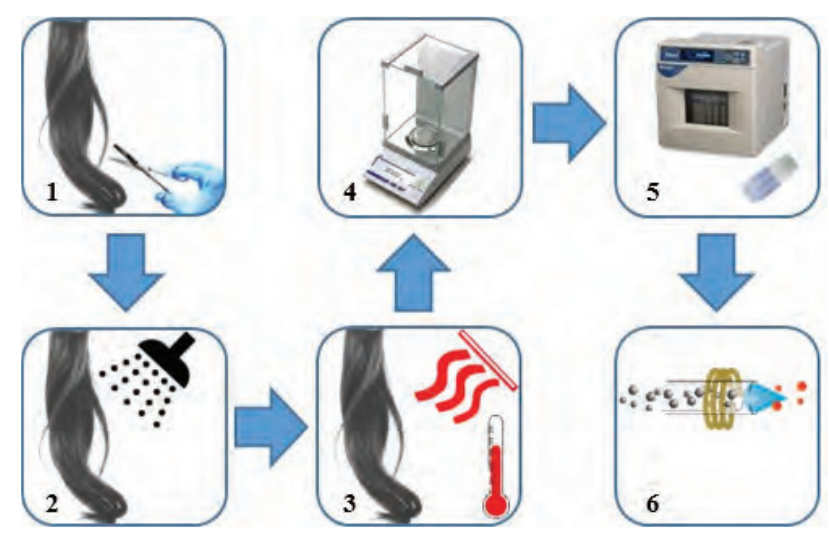

Figura 11 - Etapas do procedimento usado normalmente na quantificação de elementos químicos em cabelo. 1: Amostragem; 2: Lavagem; 3: Secagem; 4: Pesagem; 5: Digestão e diluição; 6: Quantificação

1. Amostragem - A recolha da amostra de cabelo deve ser feita em várias zonas da parte posterior da cabeça (nuca e/ou vértex posterior - Figura 12), perto da pele, com luvas e tesouras de cerâmica ou aço inoxidável, para minimizar contaminações durante o corte $[9,85]$. A recolha de várias porções de cabelo de diferentes partes da cabeça deve ser evitada, pois pode contribuir para uma maior variabilidade dos resultados, devido à existência de variações significativas na distribuição de alguns elementos ao longo do couro cabeludo [86]. A amostragem na zona posterior da cabeça é justificada pela sua menor suscetibilidade a contaminações externas, menor variabilidade na velocidade de crescimento das fibras (aproximadamente 1,0 cm/mês), menor variação do rácio entre o número de cabelos nas fases da anagénese e telogénese, menor impacto estético, presença de cabelos nessa zona mesmo em indivíduos calvos, e menor variabilidade associada aos fatores relacionados com a idade e o sexo do dador $[9,87]$.

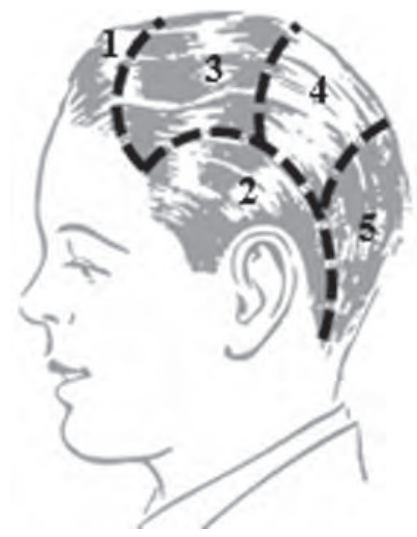

Figura 12 - Regiões do couro cabeludo. 1: Frontal; 2: Temporal; 3: Vértex superior; 4: Vértex posterior; 5: Nuca. Figura adaptada da referência [85]

2. Lavagem - Como já foi referido, esta etapa tem como finalidade remover contaminações externas, não devendo (idealmente) afetar a concentração dos elementos depositados endogenamente [85]. Os métodos mais usados são apresentados na Figura 10.

3. Secagem - Como o cabelo é higroscópico e a quantidade de água que contém depende de vários fatores, é recomendável eliminar essa fonte de variabilidade. $\mathrm{Na}$ prática, isso corresponde a calcular a concentração de analito por massa seca de cabelo. Assim, é importante garantir que toda a humidade foi eliminada, obtendo-se uma massa praticamente constante (diferença aceitável entre a massa determinada em duas pesagens sucessivas). Normalmente, a secagem é realizada numa estufa, a uma temperatura que não provoque a perda de analitos por volatilização. Após a secagem, o cabelo deve ser armazenado num exsicador, até atingir a temperatura ambiente, antes de ser pesado.

4. Pesagem - Esta etapa permite a determinação da massa de amostra seca que será usada no cálculo dos valores de concentração dos vários analitos. O principal cuidado a ter nesta etapa é a realização da pesagem de uma forma rigorosa (balança analítica), mas rápida, para evitar sobrestimar a massa pesada devido à absorção de humidade pela amostra. A quantidade de amostra a usar é definida com base em testes de homogeneidade, para assegurar a representatividade da amostra e uma quantidade suficiente para a quantificação dos analitos. No caso dos materiais de referência certificados de cabelo, que são amostras muito bem caracterizadas em termos de vários parâmetros, entre os quais a sua homogeneidade, a quantidade mínima recomendada é normalmente de $200 \mathrm{mg}$ [88]. A etapa de homogeneização das amostras de cabelo poderá passar pelo corte das fibras em pequenos pedaços e na sua mistura por agitação, o que deverá ser feito após a lavagem, para evitar promover a extração de elementos endógenos durante essa etapa devido ao aumento da área superficial provocado pelo corte da amostra.

5. Digestão e diluição - Estas etapas consistem na conversão da amostra sólida de cabelo numa solução e 
envolve a adição de pequenos volumes de ácidos inorgânicos concentrados às amostras e o aquecimento das misturas (realizado normalmente em recipiente pressurizado num forno de micro-ondas) [51]. A solução ácida permite a solubilização da maioria dos elementos numa forma estável que favorece uma adequada atomização e ionização na etapa de quantificação [89]. É importante garantir que a amostra é completamente digerida, sem que sejam introduzidas contaminações ou ocorram perdas dos analitos. A solução obtida na digestão é depois diluída com água ultrapura, para obter uma concentração final de ácido aceitável para a leitura instrumental e evitar danificar os componentes do equipamento. A diluição realizada deve ser a menor possível, para garantir que as concentrações dos vários analitos são superiores ao respetivo limite de quantificação instrumental.

6. Quantificação - As técnicas com plasma acoplado indutivamente (ICP) como fonte de atomização/ionização são as mais usadas atualmente na análise de elementos químicos em cabelo [10,51]. Comparativamente às técnicas de espetroscopia mais comuns (absorção/ emissão atómica com chama e com câmara de grafite), as técnicas de ICP são, normalmente, menos sujeitas a interferências e permitem a quantificação simultânea de vários elementos (análise multielementar) num intervalo amplo de concentrações, o que é muito útil, uma vez que as concentrações dos vários elementos químicos presentes no cabelo podem diferir entre si por várias ordens de grandeza, abrangendo uma ampla gama de trabalho [12,85]. A técnica de ICP-MS (espetrometria de massa) permite normalmente a obtenção de melhores resultados na análise de elementos vestigiais, devido à sua maior sensibilidade, à qual estão associados valores mais baixos de concentração para os limites de deteção e quantificação, comparativamente à técnica de ICP-OES (emissão atómica) [12,51].

\section{A IMPORTÂNCIA DO CONTROLO E GARANTIA DA QUALIDADE DOS RESULTADOS NA ANÁLISE QUÍMICA DE CABELO}

A correta interpretação toxicológica dos resultados obtidos na análise de cabelo pressupõe a garantia da sua qualidade, i.e. que estes refletem as características da amostra original. Falhas no método analítico podem conduzir a conclusões erróneas. É neste contexto que se destaca a importância da validação de sistemas analíticos como medida de garantia da qualidade dos resultados obtidos. De realçar que o sistema analítico engloba todo o método analítico, a matriz à qual o método será aplicado e a gama de concentração do analito [90].

Na literatura podem ser encontradas diferentes definições para o conceito de "validação". Contudo, a todas estas definições está associada a ideia de comprovar, através de evidência objetiva, que um determinado procedimento é adequado para o uso pretendido [91]. Outros conceitos importantes no contexto da metrologia química para os quais se verificam equívocos frequentes são a "exatidão”, a “justeza” e a "precisão”. Assim, na Figura 13 são apresentados esquemas que ilustram as relações existentes entre esses conceitos, considerando a última edição da versão luso-brasileira do Vocabulário Internacional de Metrologia (VIM) [92], um documento que foi criado com o objetivo de clarificar a nomenclatura.

Devido ao elevado número de etapas do método analítico referido para a quantificação de elementos químicos em cabelo, a sua validação completa é complexa. Assim, verifica-se frequentemente que essa validação se limita à técnica de quantificação, que, normalmente, é a menor fonte de incerteza [51]. A variabilidade associada às etapas de amostragem e tratamento prévio da amostra é frequentemente excluída dos procedimentos de validação executados, o que contribui para uma menor confiança nos resultados obtidos e nas conclusões apresentadas em vários trabalhos de análise química de cabelo. Esta opção pode, contudo, ser compreensível, pois a avaliação da influência de algumas etapas de pré-tratamento da amostra na qualidade dos resultados, com especial destaque para a etapa da lavagem, pode ser bastante complexa e, portanto, difícil de realizar.

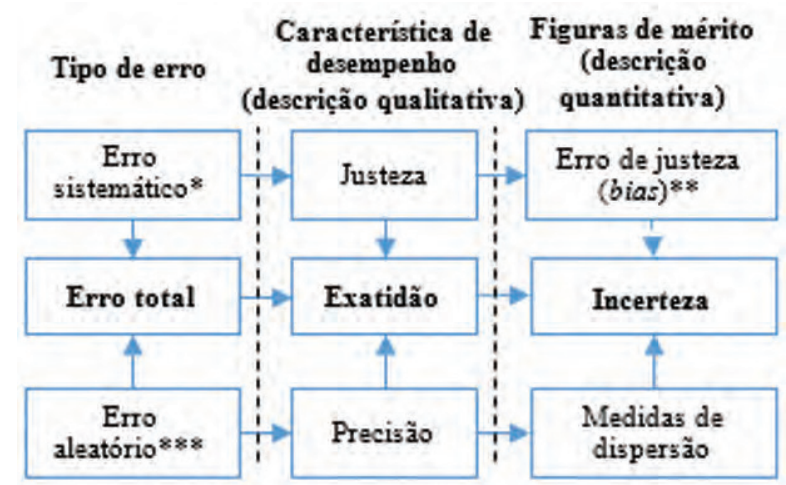

Erro - Diferença entre o valor medido e o valor de referência 8 - Componente do erro que, em mediçöes repetidas, permanece constante ou varia de forma previsivel

88 - Estimativa de um erro sistemático

8:8 - Componente do erro que, em mediçôes repetidas, varia de forma imprevisivel

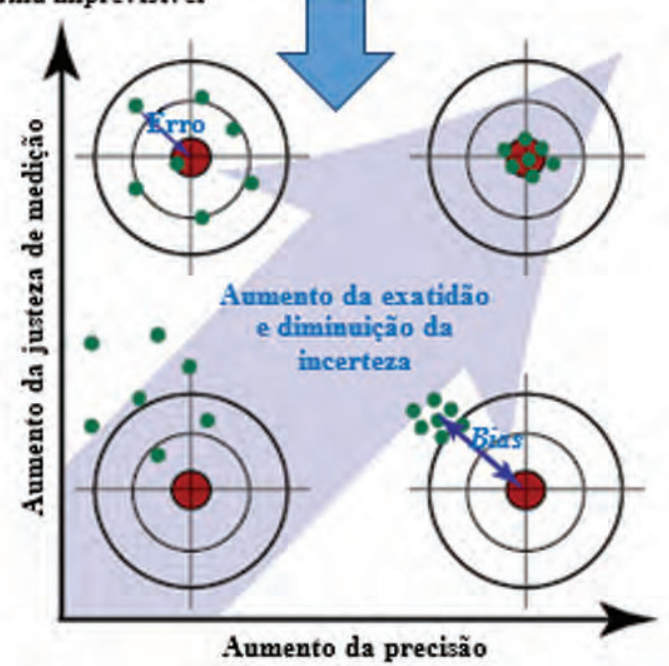

Figura 13 - Esquemas que ilustram a distinção e as relações existentes entre alguns dos conceitos mais usados em metrologia química. Figura adaptada das referências [91], [93] e [94]

A implementação de estratégias adequadas de controlo da qualidade garante a obtenção de resultados fiáveis na análise química de cabelo [95]. Essas estratégias envolvem a 
avaliação da justeza e da precisão do método. Para avaliar a justeza, pode proceder-se à digestão e análise de materiais de referência certificados de cabelo e à participação em ensaios de comparação interlaboratorial. A precisão pode ser avaliada através da aplicação do método analítico a várias réplicas de uma mesma amostra [91]. A incerteza associada à concentração calculada (medida da exatidão) poderá ser, então, estimada combinando as componentes de incerteza associadas à precisão e à justeza do sistema analítico, recorrendo às regras estatísticas de propagação da incerteza [91].

\section{CONCLUSÃO}

Embora existam muitas publicações referentes à análise química de cabelo, há ainda pouco consenso quanto à validade dos procedimentos analíticos, principalmente devido à variabilidade natural das características do cabelo e às lacunas existentes nas práticas de controlo/garantia de qualidade dos resultados. Esses fatores dificultam a afirmação inequívoca da análise química de cabelo em toxicologia. Atualmente, as entidades que realizam este tipo de análise têm vindo a demonstrar uma maior sensibilidade para as questões da qualidade dos resultados, com vista ao reconhecimento da sua competência, seguindo a tendência global que culminou na publicação da norma ISO/IEC 17025 em 1999 (documento que define os requisitos técnicos e de gestão necessários para a acreditação de laboratórios de ensaio). Contudo, é necessário desenvolver mais estudos em questões-chave da análise química de cabelo, como a lavagem e a definição de intervalos de concentração de referência.

O desenvolvimento e a validação de sistemas analíticos constituem o início do caminho a percorrer para tornar a análise de elementos químicos em cabelo um processo viável e com utilidade prática em várias aplicações, aproveitando as vantagens únicas deste tipo de matriz biológica.

\section{Agradecimentos}

Aos técnicos do serviço de ICP do Laboratório Central de Análises da Universidade de Aveiro, Lina Carvalho e Eugénio Soares, por todo o apoio prestado no âmbito do desenvolvimento da dissertação de mestrado subordinada ao tema "Desenvolvimento e validação de um método analítico para a quantificação multielementar em cabelo humano por ICP no LCA”, que esteve na origem da publicação deste artigo.

\section{REFERÊNCIAS}

[1] G. Grupe, K. Dörner, Z. Morphol. Anthropol. 77 (1989) 297-308

[2] M.R. Harkey, Forensic Sci. Int. 63 (1993) 9-18

[3] C. Robbins, "Chemical and Physical Behavior of Human Hair”, Springer-Verlag, Berlim, 2012

[4] C. Popescu, H. Hocker, Chem Soc Rev 36 (2007) 1282-1291

[5] D.L. Nelson, M.M. Cox, "Lehninger Principles of Biochemistry”, W.H. Freeman and Company, E.U.A., 2013
[6] F. Yang, Z. Yuchen, M.C. Rheinstädter, PeerJ 2 (2014) e619

[7] F. Pragst, M.A. Balikova; Clin. Chim. Acta 370 (2006) 17$-49$

[8] G.S. Choi, J. of Korean Med. Assoc. 56 (2013) 45-54

[9] S.F. Pereira, J.S. Oliveira, R. Ranjendram, Arsenic in the hair, in V.R. Preedy (ed.), "Handbook of hair in health and disease”, Wageningen Academic Publishers, Holanda, 2012, 238-254

[10] D. Pozebon, V.L. Dressler, A.J. Curtius, Quím. Nova 22 (1999) 838-846

[11] G.L. Henderson, Forensic Sci. Int. 63 (1993) 19-29

[12] J.P. Goullé, Metals, in P. Kintz (ed.) "Analytical and Practical Aspects of Drug Testing in Hair”, CRC Press, E.U.A., 2006, 343-369

[13] T.A. Hinners, W.J. Terrill, J.L. Kent, A.V. Colucci, Environ. Health Perspect. 8 (1974) 191-199

[14] V.J. Bush, T.P. Moyer, K.P. Batts, J.E. Parisi, Clin. Chem. 41 (1995) 284-294

[15] H. Mikasa, Y. Suzuki, N. Fujii, K. Nishiyama, Biol. Trace Elem. Res. 16 (1988) 59-66

[16] Blausen.com staff. "Blausen gallery 2014". Wikiversity Journal of Medicine: https://upload.wikimedia.org/wikipedia/commons/thumb/6/65/Blausen_0438_HairFollicleAnatomy_02.png/800px-Blausen_0438_HairFollicleAnatomy_02.png (Blausen Medical, acedido em 31/07/2015)

[17] I. Sunshine, Introduction, in P. Kintz (ed.) "Drug Testing in Hair”,CRC Press, E.U.A., 1996, 1-3

[18] P. Lazar, JAMA 229 (1974) 1908-1909

[19] K.M. Hambidge, Am. J. Clin. Nutr. 36 (1982) 943-949

[20] R.S. Rivlin, Am. J. Med. 75 (1983) 489-493

[21] S. Barrett, JAMA 254 (1985) 1041-1045

[22] L.M. Klevay, B.R. Bistrian, C.R. Fleming, C.G. Neumann, Am. J. Clin. Nutr. 46 (1987) 233-236

[23] R. Malter, "The Strands of Health: A Guide to Understanding Hair Mineral Analysis”, Education \& Health Resources of Arizona, E.U.A., 2003

[24] A. Cutler, "Hair Test Interpretation: Finding Hidden Toxicities”, Andrew Hall Cutler, E.U.A., 2004

[25] L. Wilson, "Nutritional Balancing And Hair Mineral Analysis”, L.D. Wilson Consultants, Inc., E.U.A., 2014

[26] “Clueless" - 15. ${ }^{0}$ episódio da 2. ${ }^{a}$ temporada da série "House M.D.”: http://www.imdb.com/title/tt0763992/ (Internet Movie Database, acedido em 30/07/2015)

[27] "Emancipation" - 8. ${ }^{\circ}$ episódio da 5. ${ }^{\mathrm{a}}$ temporada da série “House M.D.”: http://www.imdb.com/title/tt1273732/ (Internet Movie Database, acedido em 30/07/2015)

[28] "Crow's Feet" - 4. ${ }^{\circ}$ episódio da 5. ${ }^{\mathrm{a}}$ temporada da série "CSI: Crime Scene Investigation": http://www.imdb.com/ title/tt0534674/ (Internet Movie Database, acedido em 30/07/2015)

[29] W.J. Walsh, JAMA 255 (1986) 2603-2603

[30] S. Seidel, R. Kreutzer, D. Smith, S. McNeel, D. Gilliss, JAMA 285 (2001) 67-72

[31] G. Drasch and G. Roider, J. Trace Elem. Med. Biol. 16 (2002) 27-31 
[32] S. Namkoong, S.P. Hong, M.H. Kim, B.C. Park, Ann. Dermatol. 25 (2013) 67-72

[33] M.V. Jr. Kaminski, M.J. Glade, JAMA 285 (2001) 1577

[34] D.L. Watts, J.M. Mercola, JAMA 285 (2001) 1576-1577

[35] S. Seidel, JAMA 285 (2001) 1576-1578

[36] QMEQAS (Quebec Multielement External Quality Assessment Scheme): https://www.inspq.qc.ca/en/ctq/eqas/qmeqas/description (acedido em 29/07/2015)

[37] R. Agius, Drug Test. Anal. 6 (2014) 1

[38] J. Barbosa, J. Faria, F. Carvalho, M. Pedro, O. Queirós, R. Moreira e R.J. Dinis-Oliveira Bioanalysis 5 (2013) 895-914

[39] H. Sachs, Forensic Sci. Int. 84 (1997) 7-16

[40] J.L. Casper, in A. Hirschwald (ed.) "Praktisches Handbuch der gerichtlichen Medizin” (2 volumes), Berlim, 1857-1858

[41] R. W. Goldblum, L.R. Goldbaum, W.N. Piper, J. Invest. Dermatol. 22 (1954) 121-128

[42] A. Chatt, C.A. Secord, B. Tiefenbach, R.E. Jervis, Scalp hair as a monitor of community exposure to environmental pollutants, in "Hair, Trace Elements and Human Illness", Praeger Publishers, New York, 1980, 46-73

[43] Y.S. Ryabukhin (ed.), “Activation analysis of hair as an indicator of contamination of man by environmental trace element pollutants”, International Atomic Energy Agency, Agency's Laboratories, Analytical Quality Control Services, Seibersdorf (Áustria), 1976

[44] D.W. Jenkins, “Toxic trace metals in mammalian hair and nails”, Environmental Monitoring and Support Laboratory, Office of Research and Development, U.S.A. Environmental Protection Agency, E.U.A., 1979

[45] A.M. Baumgartner, P.F. Jones, W.A. Baumgartner, C.T. Black, J. Nucl. Med. 20 (1979) 748-752

[46] W. Arnold, K. Puschel, J. Forensic Sci. Soc. 21 (1981) 83

[47] O. Suzuki, H. Hattori and M. Asano, J. Forensic Sci. 29 (1984) 611-617

[48] S.B. M'Baku, R.M. Parr, J. Radioanal. Nucl. Chem. 69 (1982) 171-180

[49] "Hair Analysis Panel Discussion: Exploring the State of the Science. Summary Report”, GA: Agency for Toxic Substances and Disease Registry, Atlanta, 2001: http://www. atsdr.cdc.gov/HAC/hair_analysis/hairanalysis.pdf (ATSDR, acedido em 29/07/2015)

[50] R.J. Shamberger, Biol. Trace Elem. Res. 87 (2002) 1-28

[51] K. Chojnacka, M. Mikulewicz, Hair mineral analysis in the assessment of human exposure to metals, in V.R. Preedy (ed.), "Handbook of hair in health and disease", Wageningen Academic Publishers, Holanda, 2012, 279-292

[52] Retrato de Napoleão Bonaparte por Andrea Appiani (1805): https://commons.wikimedia.org/wiki/File:Napoleon_I_of_ France_by_Andrea_Appiani.jpg (Wikimedia Commons, acedido em 30/07/2015)

[53] J.T. Hindmarsh, CLB 35 (2002)1-11

[54] A. Lugli, A.K. Lugli, M. Horcic, Hum. Pathol. 36 (2005) 320-324

[55] A. Lugli, I. Zlobec, G. Singer, A. Kopp Lugli, L.M. Terracciano, R.M. Genta, Nat. Clin. Pract. Gastroenterol. Hepatol. 4 (2007) 52-57

[56] P. Kintz, M. Ginet, V. Cirimele, J. Anal. Toxicol. 30 (2006) 621-623
[57] S. Forshufvud, H. Smith, A. Wassen, Nature 192 (1961) 103-105

[58] H. Smith, S. Forshufvud, A. Wassen, Nature 194 (1962) 725-726

[59] S. Forshufvud, H. Smith, A. Wassén, Archiv. für Toxikologie 20 (1964) 210-219

[60] B. Weider, J.H. Fournier, Am. J. Forensic. Med. Pathol. 20 (1999) 378-382

[61] P. Kintz, J.P. Goullé, P. Fornes, B. Ludes, J. Anal. Toxicol. 26 (2002) 584-585

[62] Retrato de Ludwig van Beethoven por Joseph Karl Stieler (1820): https://commons.wikimedia.org/wiki/File:Beethoven. jpg (Wikimedia Commons, acedido a 30/07/2015)

[63] Afirmações de Walsh na conferência de imprensa a 17/10/2000 no U.S. Department of Energy's Argonne National Laboratory: http://www.sjsu.edu/beethoven/collections_exhibit/beethoven_hair/scientific_testing/testno2/ press_conference/ (Beethoven Center, San Jose State University, acedido em 22/07/2015)

[64] C. Reiter, The Beethoven Journal 22 (2007) 2-5

[65] J. Eisinger, Toxicol. Environ. Chem. 90 (2007) 1-5

[66] Retrato oficial de Andrew Jackson na Casa Branca por Ralph Eleaser Whiteside Earl (c. 1835): https://commons. wikimedia.org/wiki/File:Andrew_jackson_head.jpg (Wikimedia Commons, acedido a 30/07/2015)

[67] L.M. Deppisch, J.A. Centeno, D.J. Gemmel, N.L. Torres, J. Am. Med. Assoc. 282 (1999) 569-571

[68] Imagem de Charles Francis Hall publicada em "Harper's New Monthly Magazine” (1862): https://commons.wikimedia.org/wiki/File:Cfhall_harpers.jpg (Wikimedia Commons, acedido em 30/07/2015)

[69] F.K. Paddock, C.C. Loomis, A.K. Perkons, N. Engl. J. Med. 282 (1970) 784-786

[70] F. Antommarchi, "Les derniers moments de Napoléon ou complément du mémorial de SainteHélène”, Bruxelles: $\mathrm{H}$ Tarlier, Bruxelas, 1825

[71] K.R Henke, D.A. Atwood, Arsenic in human history and modern societies, in K. R. Henke (ed.) "Arsenic: Environmental Chemistry, Health Threats and Waste Treatment", 2009, 277-302

[72] S. Bevan, R.S. Houlston, QJM 92 (1999) 5-10

[73] Napoleon really was murdered; the weapon: " rat poison”: http://www.napoleonicsociety.com/english/2juina.htm (International Napoleonic Society, acedido em 31/07/2015)

[74] Fotografia de Ben Weider: http://www.napoleonicsociety. com/images/poison2moyen.jpg (International Napoleonic Society, acedido em 22/07/2015)

[75] Carta enviada pelo FBI a Ben Weider: http://www.napoleonicsociety.com/images/fbi.jpg (International Napoleonic Society, acedido em 22/07/2015)

[76] Comunicação oral de Pascal Kintz em Estrasburgo a 5 de Junho de 2005: http://www.napoleonicsociety.com/videos/ le_doctor/conference_video.html (International Napoleonic Society, acedido em 31/07/2015)

[77] J.A Cookson, F.D. Pilling, Phys. Med. Biol. 20 (1975) 1015-1020

[78] Vídeo da página do website do canal de televisão "History”, dedicado à controvérsia existente em torno da causa da 
morte de Napoleão Bonaparte: http://www.history.com/topics/napoleon/videos/the-death-of-napoleon (History, acedido a $03 / 08 / 2015$ )

[79] S.C. Antunes, A.C. Duarte, F. Gonçalves, R. Pereira, CAPTAR: Ciência e Ambiente para Todos 1 (2009) 136-146

[80] J. Morton, V.A. Carolan, P.H.E. Gardiner, Anal. Chim. Acta 455 (2002) 23-34

[81] J.C. Raposo, P. Navarro, A. Sarmiento, E. Arribas, M. Irazola, R.M. Alonso, Microchem. J. 116 (2014) 125-134

[82] G. Chittleborough, Sci. Total Environ. 14 (1980) 53-75

[83] M. Rabinowitz, G Wetherill, J. Kopple, Arch. Environ. Occup. Health 31 (1976) 220-223

[84] G. Chittleborough, B. J. Steel, Sci. Total Environ 15 (1980) 25-35

[85] A. Capasso, A. Loizzo, S. Caroli, Potentially toxic elements, pollution and hair, in V.R. Preedy (ed.), "Handbook of hair in health and disease”, Wageningen Academic Publishers, Holanda, 2012, 294-315

[86] I. Obrusnik, J. Gislason, D. Maes, D.K. McMillan, J. D'Auria, B.D. Pate, J. Radioanal. Chem. 15 (1973) 115-134

[87] P. Kintz, Forensic Sci. Int. 142 (2004) 127-134

[88] Certificado de análise do material de referência ERM DB001: http://www.erm-crm.org/ERM_products/search/
certificates/DB001.pdf (Joint Research Centre (JRC), European Comission, acedido a 09/09/2015)

[89] R.F. Puchyr, D.A. Bass, R. Gajewski, M. Calvin, W. Marquardt, K. Urek, M.E. Druyan, D. Quig, Biol. Trace Elem. Res. 62 (1998) 167-182

[90] J.N. Miller, J.C. Miller, "Statistics and Chemometrics for Analytical Chemistry”, Prentice Hall/Pearson Education, Reino Unido, 2010

[91] B. Magnusson, U. Örnemark (eds.), "Eurachem Guide: The Fitness for Purpose of Analytical Methods - A Laboratory Guide to Method Validation and Related Topics”, 2014

[92] A. Cruz, E. Filipe, O. Pellegrino, J.C.V. Oliveira, A.C. Baratto, S.P. de Oliveira, V.M.L. Mendoza (coordenação),”Vocabulário Internacional de Metrologia - Conceitos fundamentais e gerais e termos associados" (1. ${ }^{\mathrm{a}}$ versão luso-brasileira da 3 . $^{\mathrm{a}}$ edição internacional do VIM) IPQ, INMETRO, 2012

[93] A. Menditto, M. Patriarca and B. Magnusson, Accred. Qual. Assur. 12 (2007) 45-47

[94] Accuracy, Error, Precision, and Uncertainty: https:// www.nde-ed.org/GeneralResources/ErrorAnalysis/UncertaintyTerms.htm (NDT Resource Center, acedido a 10/08/2015)

[95] D.A. Bass, D. Hickok, D. Quig, K. Urek, Altern. Med. Ver. 6 (2001) 472-481

Actualidades CientíFICAS

\section{ROTAXANO INCORPORADO NUM MOF}

Investigadores no Canadá incorporaram pela primeira vez um rotaxano numa rede metalo-orgânica (em inglês Metal Organic Framework, MOF), criando a possibilidade de desenvolvimento de nanotecnologias em estado sólido baseadas em arquitecturas moleculares interligadas mecanicamente.

Desde que em 1991 foi reportado pela primeira vez um rotaxano em acção em solução, muitos sistemas moleculares interligados mecanicamente foram concebidos e sintetizados mostrando ser capazes de funcionar como máquinas moleculares. Um dos desafios mais importantes no desenvolvimento futuro desta química é o da organização destes sistemas moleculares- como organizar estas estruturas "inteligentes" em padrões ou em fases condensadas - uma vez que quase todos os exemplos reportados até à data têm sido caracterizados em solução, onde o movimento molecular é aleatório e incoerente. Recentemente, Kelong Zhu e colegas da Universidade de Windsor, Canadá, idealizaram uma forma de superar este obstáculo inserindo um rotaxano entre duas pontes num MOF.
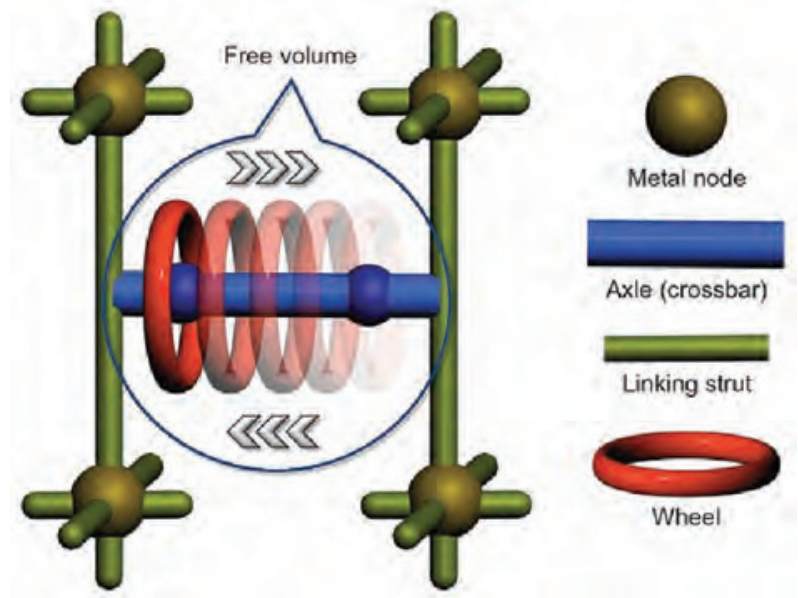

Wheel Os investigadores argumentam que este arranjo origina um movimento regular e coerente do anel macrocíclico entre as duas pontes do MOF, uma característica que é difícil de alcançar em solução, e que é um passo crucial para a obtenção de dispositivos moleculares à escala nano no estado sólido, baseados em moléculas interligadas mecanicamente.

(adaptado de "Molecular shuttle slides into the solid state”, http://www.rsc.org/chemistryworld/2015/05/ molecular-shuttle-slides-solid-state e de K. Zhu, C.A. O’ Keefe, V.N. Vukotic, R.W. Schurko, S.J. Loeb Nat. Chem., 2015, DOI: 10.1038/nchem.2258)

Paulo Mendes (pjgm@uevora.pt)

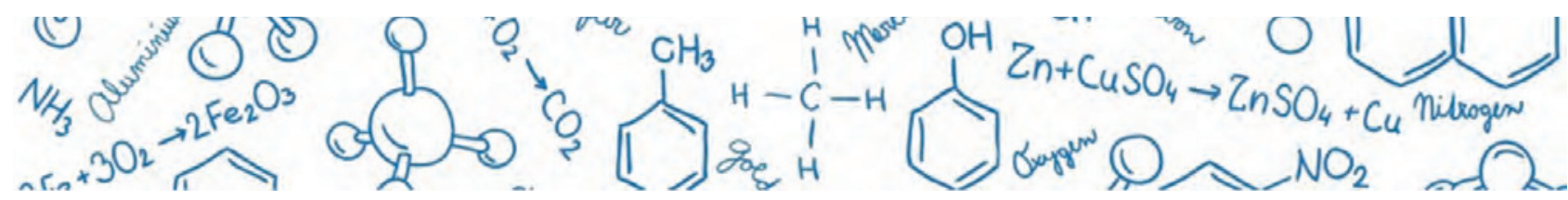

